\title{
Assessing Gender-Based Mean Differences in the Recovery Speed among COVID-19 Case Patients in Mpumalanga Province, South Africa
}

\author{
Professor Bhekizizwe Mdlovu \\ E-mail of corresponding author: bhekizm@gmail.com
}

\begin{abstract}
The primary objective of this research study was to assess whether there exist gender-based mean differences in the recovery speed from COVID-19 infection among case-patients in Mpumalanga province. A sample of 5723 case-patients in the province was used. Using the date at which the result confirming positivity for each case was received and the date at which discharge occurred, the date function in Excel was used to compute the speed of recovery, measured by the number of days. The speed of recovery from infection was computed as the number of days from first positive to first negative SARSCoV-2 PCR test result. Data was processed in Excel and Statistical Package for Social Sciences (SPSS) software prior to conducting statistical data analysis. Results show that female case patients in each age group were larger than their counterpart male case patients, while Nkangala district had the largest numbers of case patients across all age groups. The average recovery speed for male case patients was 16.89 days, with a standard deviation of \pm 7.23 days, while the mean recovery speed for female case patients was marginally lower at 16.87 days, but with a marginally higher standard deviation of \pm 7.47 days. The Levene's test for equality of variance statistics $($ F-statistic $=0.686 ; p$-value $>0.05)$ reveals no evidence of variability in the recovery speed (days) between male and female case patients.
\end{abstract}

Key words: Gender mean differences, recovery speed, Covid 19, Mpumalanga Province

DOI: $10.7176 / \mathrm{JHMN} / 80-18$

Publication date:September $30^{\text {th }} 2020$

\section{Introduction}

COVID-19 affects humans in all gender groups, and also affects other health conditions. Until a vaccine is found and approved, the pandemic will remain as a grave global health hazard. SARS-CoV-2 has been confirmed as the causative virus of COVID-19, which has rapidly become a global pandemic continuing to spread across countries in the world. Since COVID-19 is a new disease, there is much limited information regarding risk factors for severe disease. In some cases, people who get COVID-19 can become seriously ill and develop difficulties in breathing, whereas severe complications can lead to death. Populations with underlying medical conditions such as those who are immunocompromised like serious heart problems and chronic lung disease are more likely to develop serious illnesses. As more data become available, additional risk factors of severe COVID-19 may be identified. Since its outbreak worldwide, the COVID-19 pandemic has shown relatively similar proportions of cases among people in all gender groups (National Institute of Communicable Diseases, 2020).

Most of case-patients initially identified were dealers and vendors at a seafood, poultry and live wildlife market in China (WHO, 2020). In line with the global statistics, people who are most at higher risk are the elderly, individuals with co-morbidities and healthcare workers (Department of Health, 2020). The spread of the disease is believed to happen primarily via respiratory droplets produced when an infected person coughs or sneezes, similar to how influenza and other respiratory pathogens spread. Thus, the majority of cases have occurred in people with close physical contact to patient cases and healthcare workers proving healthcare to patients with COVID-19 (National Institute of Communicable Diseases, 2020). The treatment of COVID-19 is mainly supportive in form provision of oxygen for patients with some shortness of breath, coupled with other associated symptoms likes fever, dry cough and sore throat, Human antibiotics do not treat viral infections, but such antibiotics may be required if a bacterial secondary infection develops.

\subsection{Research Objective}

- To assess whether there exist gender-based mean differences in the recovery speed among COVID-19 case-patients in Mpumalanga province. 


\subsection{Research Question}

- Are there gender-based mean differences in the recovery speed among COVID-19 case-patients in Mpumalanga province?

\subsection{Research Hypothesis}

- There are no gender-based mean differences in the recovery speed among the COVID-19 among casepatients in Mpumalanga province.

\subsection{Significance of the Study}

The results from this analysis on gender-based mean differences in the recovery speed from COVID-19 infection among case-patients in Mpumalanga are expected to provide insights to both health practitioners and policy makers on health interventions that can be pursued to curb the spread of the disease among cases based on gender group. In terms of monitoring, findings can provide insights on the ways in which infection prevention and control can be directed to gender-group based case-patients.

\section{Materials and Methods}

\subsection{Design}

A descriptive research design was used in the analytical study. The categorical factor was the gender group of case patients, while the dependent variable was the "recovery speed measured in number of days".

\subsection{Population and Sample}

The population for the study was case patients who got infected and first tested positive from a first SARS CoV2 PCR test and later tested negative to SARS-CoV-2 PCR test after a certain period. The sample consists of 5 723 clinically confirmed recovered cases as at 21 July 2020.

\subsection{Data}

The secondary dataset used in the analysis was obtained from Mpumalanga Department of Health (MDoH). Data cleaning and processing was initially conducted in Excel and Statistical Package for Social Sciences (SPSS) prior to conducting statistical analysis. The variable "recovery speed (days)" was calculated by inserting the date at which the result confirming positivity was received and the date discharge occurred into the DATEDIF() function in Excel. Therefore, the time from infection to recovery is measured as the number of days from first positive to first negative SARSCoV-2 PCR test result.

\subsection{Statistical Technique}

The independent samples t-test was used to assess whether there exists a statistically significant difference between means in the recovery speed (dependent variable) across gender groups (independent categorical variable) defined by the function specified in equation (1) below:

$$
t=\frac{\overline{\mathrm{X}}_{1}-\overline{\mathrm{X}}_{2}}{\sqrt{\frac{\mathrm{S}_{1}^{2}}{\mathrm{~N}_{1}}-\frac{\mathrm{S}_{2}^{2}}{\mathrm{~N}_{2}}}}
$$

where $\left(N_{1}+N_{2}\right)-2$ is the degree of freedom (df), $\bar{x}_{1}$ is the mean recovery speed (days) of the first gender group (male) and $\overline{\mathrm{X}}_{2}$ is the mean recovery speed (days) of the second gender group (female), $\mathrm{S}_{1}^{2}$ is the standard deviation in the mean recovery speed of male case patients and $\mathrm{S}_{2}^{2}$ is the standard deviation in the mean recovery speed of female case patients, while $\mathrm{N}_{1}$ is the sample size of male case patients and $\mathrm{N}_{2}$ is the sample size of female case patients.

\section{Results and Analysis}

The frequencies and descriptive statistics are presented in Figures 1 and 2 and Tables 1 and 2 below. 
Figure 1: Distribution of cases per age group by gender

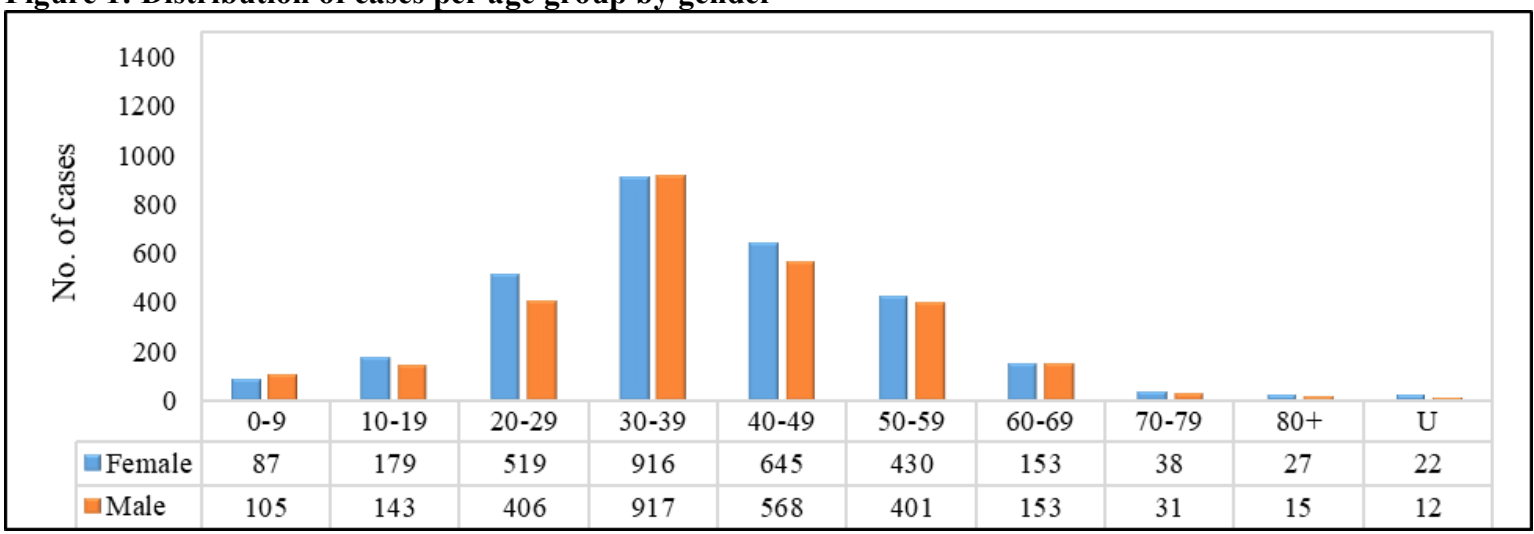

Figure 1 shows that the female case patients in each age group were larger than their counterpart male case patients, with exception of the 0-9 years age group in which there were 87 female case patients relative to 105 male case patients. Middle age groups 30-39 years and 40-49 years case patients in all gender groups accounted for the largest numbers of COVID-19 case patients in the province.

\section{Figure 2: Distribution of cases per age group by district}

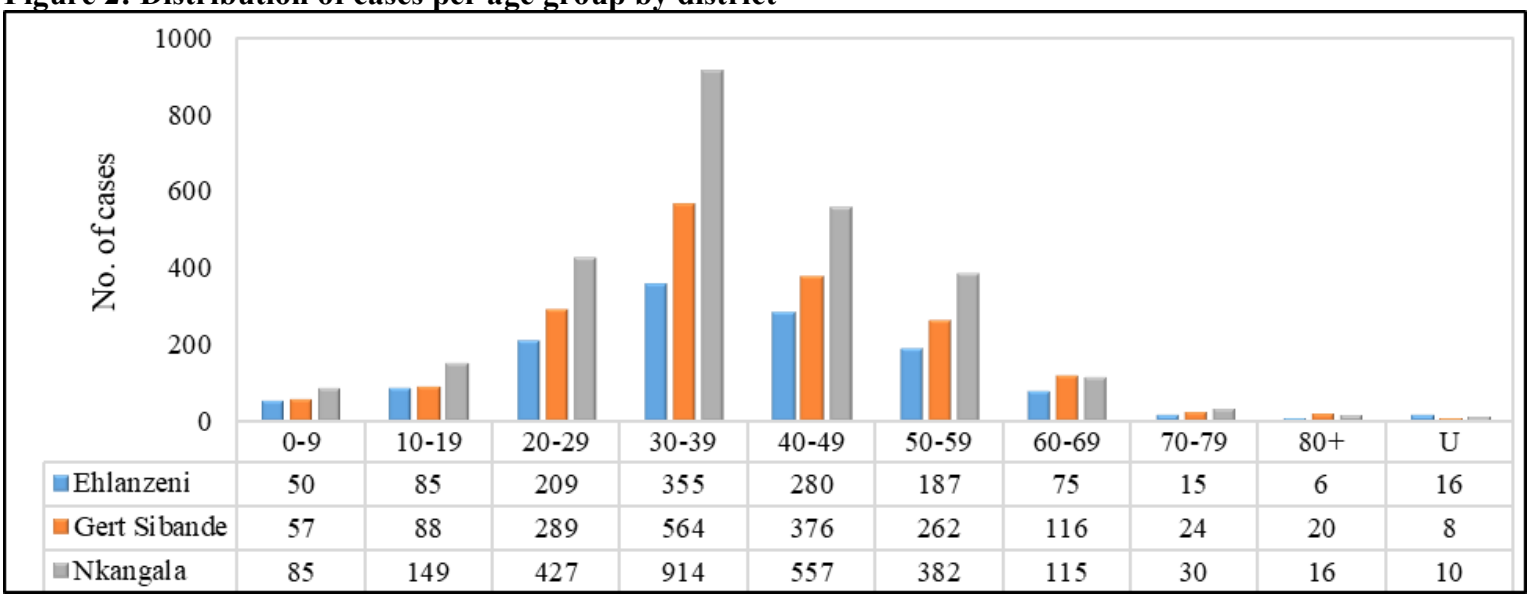

The frequencies presented in Figure 2 show that Nkangala district had the largest numbers of case patients in all age groups, except the 60-69 years in which Gert Sibande had 116 case patients while Nkangala had 115 case patients, and 80+ years age groups in which Gert Sibande had 20 case patients while Nkangala had 16 cases. Ehlanzeni district generally had the lowest numbers of case patients across all age groups.

Table 1: Gender distribution frequencies

\begin{tabular}{|l|l|c|c|}
\hline \multicolumn{2}{|c|}{} & Frequency & Percent \\
\hline \multirow{3}{*}{ Missing } & Male & 2734 & 47.8 \\
& Female & 2989 & 52.2 \\
\cline { 2 - 4 } & Total & 5723 & 100.0 \\
\hline
\end{tabular}

Table 1 gender distribution frequencies indicate that female case patients accounted for the bulk $52 \%$ of the total case patients, while the remaining $48 \%$ were male case patients. 
Table 2: Descriptive statistics

\begin{tabular}{|l|l|c|c|c|}
\hline & Gender & N & Mean (std dev) & Std. Error Mean \\
\hline \multirow{2}{*}{ Recovery speed (days) } & Male & 2734 & $16.89 \pm 7.23$ & .138 \\
& Female & 2989 & $16.87 \pm 7.47$ & .137 \\
\hline
\end{tabular}

Table 2 descriptive statistics show that the average recovery speed for male case patients was 16.89 days, with a standard deviation of \pm 7.23 days, while the mean recovery speed for female case patients was marginally lower at 16.87 days, but with a marginally higher standard deviation of \pm 7.47 days. Results of the average differences in the recovery speed between the gender groups are presented in Table 3 below.

Table 3: Independent samples test

\begin{tabular}{|c|c|c|c|c|c|c|c|c|c|c|}
\hline & \multicolumn{2}{|c|}{$\begin{array}{l}\text { Levene's Test } \\
\text { for Equality } \\
\text { of Variances }\end{array}$} & \multicolumn{7}{|c|}{ t-test for Equality of Means } \\
\hline & & \multirow[t]{2}{*}{$\mathrm{F}$} & \multirow[t]{2}{*}{ Sig. } & \multirow[t]{2}{*}{$\mathrm{t}$} & \multirow[t]{2}{*}{ df } & \multirow[t]{2}{*}{$\begin{array}{l}\text { Sig. (2- } \\
\text { tailed) }\end{array}$} & \multirow{2}{*}{$\begin{array}{l}\text { Mean } \\
\text { Differe } \\
\text { nce }\end{array}$} & \multirow{2}{*}{$\begin{array}{c}\text { Std. } \\
\text { Error } \\
\text { Differe } \\
\text { nce } \\
\end{array}$} & \multicolumn{2}{|c|}{$\begin{array}{l}95 \% \text { Confidence } \\
\text { Interval of the } \\
\text { Difference }\end{array}$} \\
\hline & & & & & & & & & Lower & Upper \\
\hline \multirow{2}{*}{$\begin{array}{l}\text { Recovery } \\
\text { speed } \\
\text { (days) }\end{array}$} & $\begin{array}{l}\text { Equal } \\
\text { variances } \\
\text { assumed }\end{array}$ & .686 & .408 & .090 & 5721 & .929 & .017 & .195 & -.364 & .399 \\
\hline & $\begin{array}{l}\text { Equal } \\
\text { variances not } \\
\text { assumed }\end{array}$ & & & .090 & 5702.42 & .929 & .017 & .194 & -.364 & .398 \\
\hline
\end{tabular}

The Levene's test for equality of variance statistics (F-statistic $=0.686$; $p$-value $>0.05$ ) reveals no evidence of variability in the recovery speed (days) between male and female case patients. The mean differences are not statistically significantly different $(\mathrm{p}=0.408)$, hence the null hypothesis of equal variances could not be rejected. Therefore, results of the Equal variances not assumed should not be used, whose t-statistic $=0.090$ and a mean difference $=0.017$ calculated by subtracting the mean of the second group (female case patients) from the mean of the first group (male case patients). The computed mean difference equal to 0.017 lies within the computed confidence interval of the difference.

\section{Conclusion and Recommendations}

This research study found no evidence of statistically significant differences in the average recovery speed (days) from COVID-19infection between male and female case patients. The findings imply that provision of clinical and health-related interventions aimed at curbing the spread of the COVID-19 disease should not be differentiated based on gender since the average recovery speed among case-patients in all gender groups is not significantly different. ages. Concurrently, follow-ups on recovery cases should be conducted in a standardised manner as well, predominantly with close monitoring on case-patients who might have comorbidities and chronic health conditions.

\section{References}

Department of Health. (2020). Corona Virus(COVID-19) Pandemic. Republic of South Africa.

World Health Organisation. (2019). Coronavirus disease (COVID-19) pandemic.

https://www.who.int/emergencies/diseases/novel-coronavirus-2019

World Health Organisation. (2020). Clinical management of severe acute respiratory infection when COVID-19 is suspected. 13 March 2020. https://www.who.int/publications-detail/clinical-management-of-severe-acuterespiratory-infection-when-novel-coronavirus-(ncov)-infection-is-suspectedexternal icon

World Health Organisation. (2020). The Novel Coronavirus Pneumonia Emergency Response Epidemiology Team. (2020). The epidemiological characteristics of an outbreak of 2019 novel coronavirus diseases (COVID19) - China 2020. CCDCweekly.10.46234/ccdcw2020.03210.46234/ccdcw2020.032external icon10.46234/ccdcw2020.032external icon 10.46234/ccdcw2020.032external icon 
World Health Organisation. (2020). Infection prevention and control during health care when novel coronavirus $(\mathrm{nCoV})$ infection is suspected. https://www.who.int/publications-detail/infection-prevention-and-control-duringhealth-care-when-novel-coronavirus-(ncov)-infection-is-suspected-20200125external icon

World Health Organisation. (2020). Rational use of personal protective equipment for coronavirus disease (COVID-19) and considerations during severe shortages https://apps.who.int/iris/bitstream/handle/10665/331695/WHO-2019-nCov-IPC PPE use-2020.3-eng.pdfpdf iconexternal icon 